\title{
STUDY OF ANGIOGENIC POTENTIAL OF MORINGA OLEIFERA LAM. ON CHICKEN CHORIOALLANTOIC MEMBRANE (CAM)
}

\begin{tabular}{|l|l|l|l|l|l|l|l|}
\hline Physiology &
\end{tabular}

\begin{tabular}{ll} 
Vijaykumar & Assistant Professor \& PhD Scholar, Dept. of Physiology, D Y Patil University, School of \\
Gupta* & Medicine Navi Mumbai, India. *Corresponding Author \\
\hline Vivek Nalgirkar & $\begin{array}{l}\text { Professor \& Head, Dept. of Physiology, D Y Patil University, School of Medicine Navi } \\
\text { Mumbai, India. }\end{array}$ \\
\hline
\end{tabular}

Geetanjali Gajanan Ranade Yash Kripalani

Researcher Goldfield Fragrances Pvt. Limited Prabhadevi, Mumbai, India

Tutor and research fellow, dept. of Physiology, D Y Patil University, School of Medicine, Navi Mumbai, India.

\section{ABSTRACT}

Angiogenesis plays an important role in many physiological and pathological conditions. Currently, the drugs possessing pro-angiogenic property as compared to anti-angiogenic property are limited. The primary objective of study was to find the angiogenic potential of hot methanolic extract of leaves of Moringa Oleifera Lam. The hot methanolic extract of moringa leaves was prepared using soxhlet extraction. Phytochemical analysis was done by thin layer chromatography, ultra violet and infrared spectrophotometer. The egg candling instrument was prepared indigenously to observe the angiogenesis in Chick Chorioallantoic Membrane (CAM) model of hen's egg. The eggs obtained from Aarey Poultry, Goregaon (Mumbai) were observed for their fertility and Embryonic Development Day (EDD). The growth of embryo was observed every day till 7 th day of EDD. The test sample was loaded on 8th day and the angiogenic effect was observed and photographed every day till 11th day. The PlerminTM ointment ( $\beta \beta$ PDGF) (Platelet Derived Growth Factor) was used as positive control. Quantification of blood vessels was done with growth index [(No of BLVS11 th day - no of blood vessels 8th day)/ No of BLVS11 th day], Abgel@ sponge assay and compared with PDGF.

\section{KEYWORDS}

Arteries, Chorioallantoic Membrane, Angiogenesis, Moringa Oleifera, Chromatography, Healing

\section{INTRODUCTION}

Angiogenesis is the development of new blood vessels from the preexisting blood vessels. It is a highly regulated process from fetal life till the death of an organism. Angiogenesis plays a significant role in various physiological functions, normal growth and various pathologies. Many diseases can occur due to uncontrolled angiogenesis like vascular tumors, solid carcinomas, macular degeneration etc. Similarly, several complications like delayed wound healing, ischemia, ulcers, decreased somatic growth etc. can occur due to insufficient angiogenesis. Therefore, many diseases can invariably be treated or controlled by modulating the process of angiogenesis ${ }^{(1)}$

The list of drugs used to modulate angiogenesis is small and that of compounds from plant origin to modulate angiogenesis is still smaller. Therefore, therapeutic intervention to improve angiogenesis can be of significant value in clinical practice. There is wide use of Moringa as a wound healing agent in folklore medicine ${ }^{(2)}$.

The Pro-angiogenic property of Moringa oleifera commonly known as drumstick tree was tested. The extracts of dried leaves of Moringa are tested for their efficacy on angiogenesis. To experimentally study angiogenic potential, the Chick Embryo Chorioallantoic Membrane (CAM) model was chosen. The model was chosen because of its simplicity, rapidity, and low cost. The CAM is also used widely in preclinical in vivo studies ${ }^{(3)}$. The CAM is an extra embryonic membrane used to observe the angiogenic effect of drug. The membrane starts developing on $3^{\text {rd }}$ day of embryonic development day (EDD) and the density of vessels can be changed and photographed for analysis. If the drug is pro-angiogenic then the density of blood vessels in CAM increases and if the drug is anti-angiogenic then the density of blood vessels decreases around the drug testing area on the membrane. The plant extract is loaded on CAM on $8^{\text {th }}$ day and results are visualized on $11^{\text {th }}$ day of (EDD). The efficiency of leaf extract is compared against Plermin $^{\mathrm{TM}}$ an ointment containing ( $\beta \beta$ PDGF) a known compound for angiogenesis ${ }^{(2)(4)}$.

\section{METHODOLOGY}

\section{Preparation of Plant Extract.}

The fresh leaves of Moringa oleifera were obtained from single tree from Palghar district of India. The leaves were shade dried for 20 days till the crackling sound were heard when they are crushed with hands. The Hot Methanolic extract was prepared from leaves and preserved in amber colored bottle. The property of extract was determined according to protocols available in Ayurvedic Pharmacopeia

\section{Chick Chorioallantoic Membrane (CAM) Study}

The fresh fertilized white leghorn eggs Gallus gallus were obtained from Central poultry development organization, Aarey milk colony, Goregaon Mumbai. The embryonic development day (EDD) of the eggs is determined by trans-illumination using egg. It is confirmed that all the eggs have same EDD. The eggs were cleaned with $70 \%$ alcohol and kept in humidified Incubator and the temperature was maintained at $37^{\circ}$ Centigrade. The eggs were marked and turned every 1 hour to facilitate normal growth of embryo till $7^{\text {th }}$ day of $\operatorname{EDD}{ }^{(6)}$. On $2^{\text {nd }}$ day the pointed end of the egg is swabbed with neat Betadine and a small hole made in the shell using a dental drill bit $1 \mathrm{~mm}$ and subsequently $2 \mathrm{ml}$ of albumen is aspirated from egg this provides the lager working area in the egg for subsequent procedures. The eggs were just observed unopened till $5^{\text {th }}$ day and on $6^{\text {th }}$ day the eggs were opened from broad end. The opened end of the eggs is covered with adhesive tape to avoid the loss of moisture from eggs. The test sample was applied on CAM on $8^{\text {th }} \mathrm{EDD}^{(7)}$. The eggs were divided in 3 groups. One group was used for test sample extract. Second group is used as a positive control group. And third group is used as a blank control.

\section{Disc Method for Sample Application}

The test sample is applied by loading 20 microliters of methanolic extract on $2 \mathrm{~mm}$ disc of Whatman filter paper no. 1 and air dried for 1 hour before loading sample on CAM. Similarly, Plermin ${ }^{\mathrm{TM}}$ by Dr. Reddy's, ( $\beta \beta$ PDGF) (Platelet Derived Growth Factor) is used as a positive control. And only methanol is loaded on blank control. One egg is also kept in incubator as an incubator control.

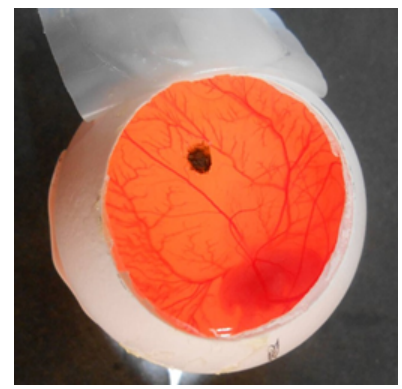

Figure I. CAM on $8^{\text {th }}$ Day 


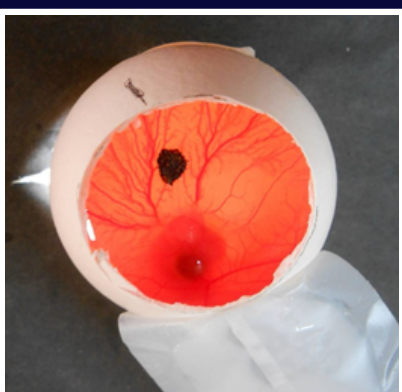

Figure II. CAM on $11^{\text {th }}$ Day

\section{Sponge Method for sample application}

In this method the test and standard samples were prepared of suitable concentration using $0.9 \%$ normal saline as a diluent. The sterilized small blocks of size $2 \mathrm{~mm} 3$ of AbGelTM was cut from its large block. The small blocks were dipped into the samples and were soaked for 4 hrs. The soaked blocks were then placed on CAM. The angiogenic activity of the drug will allow the vessels to infiltrate the sponge and these sponge blocks are sectioned from CAM. The blocks are stored in $1 \%$ formaldehyde solution and then analyzed by histopathology using $\mathrm{H} \& \mathrm{E}$ staining technique (7). The neovascularization can be observed and counted by stained endothelial cells (figure 1).

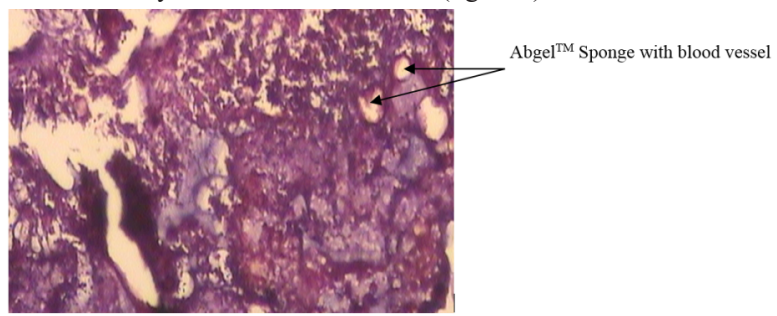

Figure III. Slide showing sponge-tissue interphase at 100x, H \& E stain Larae number blood vessels can be seen in sponqe

\section{Statistics}

Using the one-way analysis of variance (ANOVA) the P value obtained is 0.0021 . It is considered significant for this study. The mean value for each column vary significantly greater than expected.

Table I. Comparison between Moringa and Plermin

\begin{tabular}{|l|l|l|l|}
\hline Comparison & $\begin{array}{l}\text { Mean } \\
\text { Difference }\end{array}$ & q & P value \\
\hline $\begin{array}{l}\text { MOG vs } \\
\text { Plermin }\end{array}$ & -21.297 & $2.741 \mathrm{~ns}$ & $\mathrm{P}>0.05$ \\
\hline
\end{tabular}

Table II. Mean difference between Moringa and Plermin

\begin{tabular}{|r|c|c|c|}
\hline \multirow{2}{*}{ Difference } & Mean & \multicolumn{2}{|c|}{$95 \%$ Confidence interval } \\
\cline { 3 - 4 } & Difference & From & To \\
\hline MOG - Plermin & -21.297 & -49.097 & 6.504 \\
\hline
\end{tabular}

The table above indicates the use of Tukey-Kramer multiple comparison test. Here Moringa Oleifera (MOG) is compared to Plermin and conclusions are derived accordingly. The second column indicates the mean difference, whereas, the third and fourth column indicate $\mathrm{q}$ and $\mathrm{P}$ values respectively. Here the $\mathrm{q}$ value is less than 3.578 hence the $\mathrm{P}$ value is greater than 0.05 according to the test.

Assumption test were done using the Bartlett's method where ANOVA assumed that the samples were collected from populations with identical standard deviations. This test could be only performed when each column has more than five values.

ANOVA also assumed that the data sampled from the populations follow Gaussian distributions. This assumption was done with Kolmogorov and Smirnov method. The following table contains the information for this method.

Table III. Normality test of Moringa and Plermin

\begin{tabular}{|l|l|l|l|}
\hline Group & KS & P value & Passed normality Test \\
\hline MOG & 0.2090 & $>0.10$ & Yes \\
\hline Plermin & \multicolumn{3}{|c|}{ Too few values to test } \\
\hline
\end{tabular}

The first column contains the groups of the test samples used in the study which are moringa Oleifera and Plermin. The second and third column indicates the KS value and $\mathrm{P}$ value. The fourth column indicates whether it passed the normality test. The values provided are for only Moringa Oleifera as Plermn had too few values to test.

Table IV. Intermediate Calculations and ANOVA table

\begin{tabular}{|l|l|l|l|}
\hline $\begin{array}{l}\text { Source of } \\
\text { variation }\end{array}$ & Degrees of freedom & Sum of squares & Mean Sqare \\
\hline $\begin{array}{l}\text { Treatments } \\
\text { (between } \\
\text { columns) }\end{array}$ & 2 & 4755.3 & 2377.7 \\
\hline $\begin{array}{l}\text { Residuals } \\
\text { (within columns) }\end{array}$ & 20 & 5572.8 & 278.64 \\
\hline Total & 22 & 10328.1 & \\
\hline
\end{tabular}

$\mathrm{F}=8.533$ (MS treatment/MS Residual)

Table V. Summary of Data

\begin{tabular}{|l|l|l|l|l|l|}
\hline Groups & $\begin{array}{l}\text { Number of } \\
\text { points }\end{array}$ & Standard mean & $\begin{array}{l}\text { Standard } \\
\text { error of } \\
\text { Deviation }\end{array}$ & Mean & Median \\
\hline MOG & 10 & 32.870 & 19.079 & 6.033 & 38.750 \\
\hline Plermin & & 54.167 & 12.332 & 7.120 & 60.000 \\
\hline
\end{tabular}

Table VI. 95\% confidence interval

\begin{tabular}{|l|l|l|l|l|}
\hline Group & Minimum & Maximum & From & To \\
\hline MOG & 0.000 & 50.000 & 19.222 & 46.518 \\
\hline Plermin & 40.000 & 62.500 & 23.529 & 84.804 \\
\hline
\end{tabular}

\section{Table VII. Collection of all Data}

\begin{tabular}{|l|l|l|}
\hline Collection of Titles & MOG (A) & Plermin (B) \\
\hline Mean & 32.87 & 54.166667 \\
\hline Standard Deviation (SD) & 19.079 & 12.332 \\
\hline Sample Size (N) & 10 & 3 \\
\hline Standard Error of Mean (SEM) & 6.033 & 7.120 \\
\hline Lower 95\% Confidence limit & 19.222 & 23.529 \\
\hline Upper 95\% Confidence limit & 46.518 & 84.804 \\
\hline Minimum & 0.000 & 40.000 \\
\hline Median (50th Percentile) & 38.750 & 60.000 \\
\hline Maximum & 50.000 & 62.500 \\
\hline Normality Test KS & 0.2090 & Too few values \\
\hline Normality Test P value & $>0.10$ & \\
\hline Passed Normality test? & Yes & \\
\hline
\end{tabular}

Table VIII. Values of Moringa Oleifera abgel dose against growth

\begin{tabular}{|l|l|}
\hline Concentration of Moringa Oleifera & Growth \\
\hline 1685 & 50.0 \\
\hline 1685 & 40.0 \\
\hline 3370 & 37.5 \\
\hline 3370 & 50.0 \\
\hline 5055 & 33.3 \\
\hline 5055 & 42.9 \\
\hline 6740 & 50.0 \\
\hline 6740 & 0.00 \\
\hline 8425 & 25.0 \\
\hline 8425 & 0.00 \\
\hline
\end{tabular}

Graphical representation in the form of Bar graph is provided below

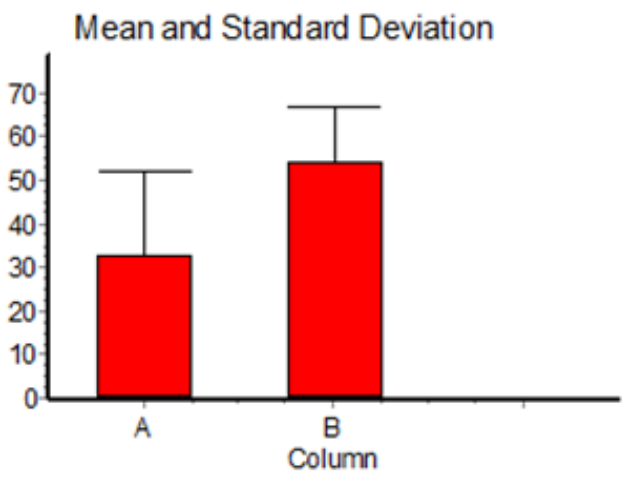

Figure IV. 
Mean and Standard Error

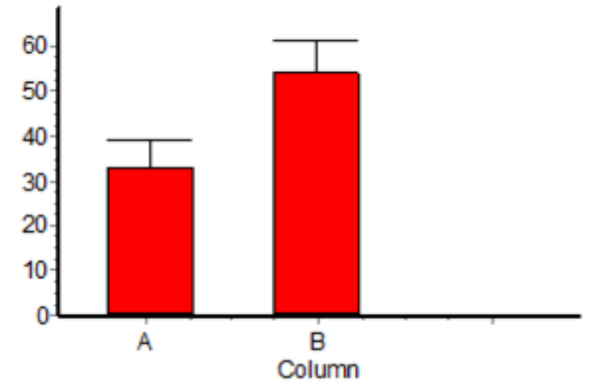

Figure V.

Linear Regression

Number of points $=10$

Best - Fit standard $95 \%$ confidence level interval

Table IX. Linear Regression in tabular format.

\begin{tabular}{|l|l|l|l|l|}
\hline Parameter & Best-Fit & \multirow{2}{*}{$\begin{array}{l}\text { Standard } \\
\text { Error }\end{array}$} & \multicolumn{3}{|c|}{ 95\% Confidence interval } \\
\cline { 4 - 5 } & Value & from & to \\
\hline Slope & -0.004970 & 0.002031 & -0.009653 & -0.0002875 \\
\hline Y intercept & 57.995 & 11.349 & 31.825 & 84.165 \\
\hline X intercept & 11668 & \multicolumn{3}{|l}{} \\
\hline
\end{tabular}

Correlation Coefficient $(\mathrm{r})=-0.6544$

$\mathrm{r}^{2}=0.4282$

Standard deviation of residuals from line $(\mathrm{S} y . \mathrm{x})=15.303$

We need to know if the slope is significantly different from 0 . The $\mathrm{p}$ value here is 0.0401 , which is considered significant. This result was obtained from the following ANOVA table

Table X. Source of variations.

\begin{tabular}{|l|l|l|l|}
\hline Source of variation & Degrees of Freedom & $\begin{array}{l}\text { Sum of } \\
\text { squares }\end{array}$ & $\begin{array}{l}\text { Mean } \\
\text { Square }\end{array}$ \\
\hline $\begin{array}{l}\text { Linear regression } \\
\text { (model) }\end{array}$ & 1 & 1402.8 & 1402.8 \\
\hline $\begin{array}{l}\text { Deviations from } \\
\text { linearity (Residual) }\end{array}$ & 8 & 1873.4 & 234.17 \\
\hline Total & 9 & 3276.2 & \\
\hline
\end{tabular}

$\mathrm{F}=5.991$

\section{Standard Curve representation}

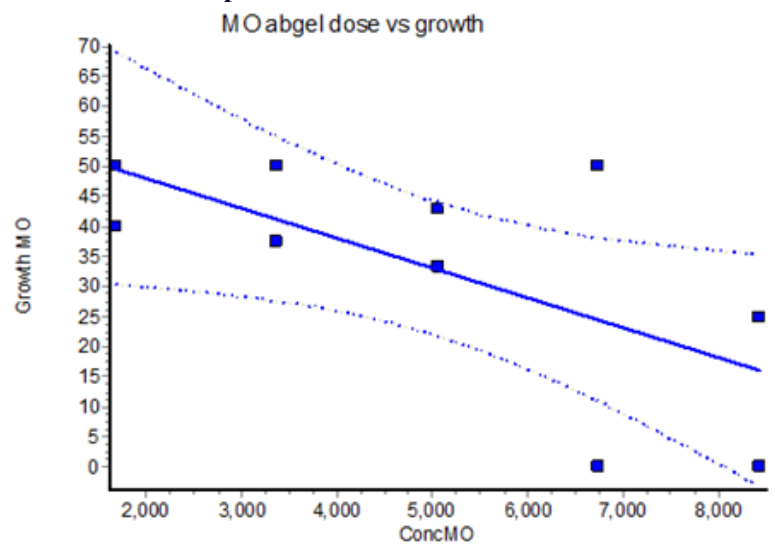

Figure VI. In the above graphical representation growth of moringa Oleifera is plotted on $\mathrm{Y}$ axis against concentration of Moringa Oleifera on X axis.

\section{RESULTS}

The Methanolic extract of Moringa leaves have shown strong angiogenic property when compared with Plermin ${ }^{\circ}$ owing to its inflammatory response in CAM. Its phytochemical constituents are Arbutin, Anthraglycosides, Alkaloids, Flavonoids, Cardiac glycosides and Bitter principles the study suggests that Moringa Leaves possess a very strong angiogenic property and can be used as a natural substance instead of synthetic substances for Angiogenesis. In the photograph of
CAM on $11^{\text {th }}$ day, there is visible increase in growth of Blood vessels in Moringa and Plermin. According to Tukey-Kramer Multiple Comparisons Test the $\mathrm{p}$ value is greater than $(\mathrm{P}>0.05)$ of moringa compared to Plermin. If the value of $\mathrm{q}$ is greater than 3.578 then the $\mathrm{P}$ value is less than 0.05 . A visible growth of blood vessels is seen in the CAM where moringa is applied as an angiogenic agent. It is comparable to Plermin which is known for its angiogenic potential This shows that moringa Oleifera can be used as a potent natural substance to produce angiogenesis instead of a synthetically manufactured product

\section{DISCUSSION}

Impaired wounds healing may occur in any individual but are more frequent in the elderly and chronically ill people. With an ageing population and a dramatically increasing prevalence of chronic diseases like cancer, diabetes, wound care will certainly become an even more noteworthy issue for health systems. Delayed wound healing is signified with alteration in physical properties of collagen, flattening of the dermo-epidermal junctions, nutritional depletion and cellular immunity leading to abnormal changes in pro-inflammatory and anti-inflammatory cytokines. A number of evidence has been collected to show immense potential of medicinal plants used in various traditional systems.

Moringa Oleifera is known to improve wound healing and aid in stunting bacterial growth. It is widely used in traditional medicine. The extract of this plant is used to study its angiogenic potential in the chorioallantoic membrane of the chick embryo. It is compared against plermin which is well known for inducing angiogenesis as a control. The utilisation of CAM for testing angiogenesis and anti-angiogenesis has become popular during the last 3 decades comprising of over 150 publications in 2003-04. The CAM is an alternative to animal model and provides a natural environment to grow blood vessels. The principle is to explant cells, tissue etc. on CAM directly to test substances implicated in angiogenesis in order to evaluate alterations in its natural of induced angiogenic capacity. Angiogenesis in CAM comprises of two different mechanisms, endothelial sprouting and intussusceptive microvascular growth (IMG). Endothelial sprouting is based on cell migration, proliferation and tube formation. IMG divides the vessels lumens by formation and insertion of tissue structure and pillars or post. The CAM assay has multiple advantages such as low cost, relative ease of preparation and carrying out various studies, simplicity, absence of mature immune system in avian embryos, more reliability, and readily available and feasible as an agent to conduct this study.

The required material was obtained and prepared accordingly, the extract was loaded on the CAM on the 8th day and observations were made throughout.

As per the observation, there was visible increase in blood vessels on the 11th day in both the control and the sample loaded with moringa extract which has been photographed, on the contrary, the CAM sample not loaded with any drug did not show improvement in angiogenesis. The study suggests that Moringa Leaves possess a very strong angiogenic property and can be used as a natural substance instead of synthetic drugs for Angiogenesis.

\section{Author Contributions}

Vijaykumar Gupta is the corresponding author and has led the research along with his team of four researchers mentioned above. Dr. Vivek Nalgirkar has been a guide and mentor to Mr. Vijaykumar Gupta and his team in conducting this research. Geetanjali Gajanan Ranade has provided a tremendous help in providing materials required to conduct this research. Dr. Yash kripalani has also provided support in editing and writing up the research manuscript along with observations made throughout the project.

\section{Funding}

This research received no specific grant from any funding agency in the public, commercial, or not-for-profit sectors.

\section{Declaration of conflict of interests}

The authors declared no potential conflicts of interest with respect to the research, authorship, and/or publication of this article.

\section{REFERENCES}

1. Judah Folkman, 1972. Antiangiogenesis: New concept for therapy of solid tumors. 
Annals of Surgery. Mar 175(3),409-416.

2. Shanshan Wanga, Zhengui Zheng et al. Angiogenesis and anti-angiogenesis activity of Chinese medicinal herbal extracts. Jrnl. of life sciences 74(2004)2467-2478.

3. Angelica Vargas, Magali Zeisser-Labouèbe, The chick embryo and its chorioallantoic membrane (CAM) for the in vivo evaluation of drug delivery systems, Advanced Drug Delivery Reviews 59(2007)1162-1176

4. Maija Bry, Riikka Kivelä et al. Vascular endothelial growth factor-b in Physiology and disease. Physiol Rev 94:779-794,2014.

5. Government of India ministry of health and family welfare, department of ayush The Ayurvedic Pharmacopoeia Of India; Appendix-1, 139-146.

6. Department of Anatomy and Embryology, University College London, Gower Street, W.C., U.K. A critical period for the turning of hens' eggs J. Embryol. exp. Morph. Vol. 5, Part 3,pp. 293-299, September 1957.

7. J. Clifford Murray, Methods in molecular medicine, Angiogenesis Protocols., Humana Press Inc., Totowa, NJ, Vol. 46, 107-130. 